\title{
Numerical simulation of elastic stress in the microstructure of snow
}

\author{
MARTIN SCHNEEBELI \\ WSL Swiss Federal Institute for Snow and Avalanche Research, SLF, Flüelastrasse 11, CH-7260 Davos-Dorf, Switzerland \\ E-mail:schneebeli@slf.ch
}

\begin{abstract}
The mechanical properties of snow depend on its microstructure. The fabric of snow was reconstructed in three dimensions using serial sections or X-ray microtomography. A voxel-based finite-element model, with the elements based on the microstructure and ice as the material, was used to calculate the stress distribution in the snow. A small elastic deformation was simulated and the bulk elastic moduli of these samples were determined. The simulated elastic modulus was 3-10 times or 10-100 times larger than previously published measurements. The deviation is possibly caused by the relatively slow deformation rates of the usual tests. This strain-rate effect is well known for pure ice. Locations of stress concentrations can be extracted and compared to the microstructural location of bonds. By this method we are able to determine mechanical properties of thin or extremely brittle snow layers which are otherwise difficult or impossible to measure.
\end{abstract}

\section{INTRODUCTION}

The apparent mechanical and physical properties of snow depend not only on the density but also on the fabric (microstructural arrangement of the snow crystals). Shapiro and others (1997) reviewed snow mechanics and found that no current system of snow classification is satisfactory, because no unique dependence between mechanical property, density and snow type is possible. Sturm and others (1997) showed the importance of microstructure for the thermal conductivity of snow. However, they found no clear correlation between snow type and thermal conductivity and concluded that current snow classification techniques cannot be used to determine physical properties. A similar problem occurs in the analysis of mechanical properties of trabecular bones (Ford and Keaveny, 1996). Stereological methods based on vertical sections are insufficient to achieve good correlations between fabric and mechanical properties. Direct finite-element simulation of elastic properties using three-dimensional reconstruction techniques by serial sectioning or X-ray microtomography circumvents the correlation between stereological and mechanical parameters (Van Rietbergen and others, 1995). The three-dimensional reconstruction of casted and undisturbed snow samples is now possible using serial sections (Schneebeli, 2001) or X-ray microtomography (Coléou and others, 2001; Schneebeli, 2002). On the other hand, direct measurement of mechanical and physical properties of snow samples is difficult due to the inherent fragility of snow and sometimes to very thin layers. In this study, a finite-element (FE) simulation technique was used to investigate the microstructural stress distribution in different snow types. The elastic stress of snow was simulated in order to derive the elastic modulus with polycrystalline ice as material. The stress concentrations in heterogeneous fabrics, such as occur in weak layers, were simulated and a possible fracture mechanism was derived.

\section{MATERIAL AND METHODS}

\section{Material}

Two samples of snow were used: one was natural snow sieved into a sample container, subjected to a temperature gradient and imaged at different stages of temperature-gradient metamorphism at the same spatial location without disturbing the sample, called TG; the other was from a natural weak layer of 29 January 1999, called WK. The TG sample was used to investigate the effect of microstructure on the elastic modulus without changing the density; the WK sample was used to investigate the effect of a very layered microstructure on stress distributions.

The TG sample was prepared from the snow which was stored for several months in a cold room, and was sieved into a small cylinder $48 \mathrm{~mm}$ in diameter. The volume fraction was 0.266 and the density $243 \mathrm{~kg} \mathrm{~m}^{-3}$. A temperature gradient of $100 \mathrm{~K} \mathrm{~m}^{-1}$ was applied over 6 days. The sample was scanned non-destructively with an X-ray computer tomograph (Scanco $\mu$-CT80) with a resolution of $36 \mu \mathrm{m}$ at four stages of metamorphism. The scanning was performed at the start (TG 1), after 1 day (TG 2), after 3.5 days (TG 3) and after 6 days (TG 4). The segmentation of the ice matrix from the images was done such that the porosity was constant. Total mass and mass distribution was checked at the start and at the end of the measurements. Unconnected parts of the ice matrix, which was $<2 \%$ of the total ice, were removed for the FE simulation. The four reconstructed cubes had a side-length of $3.6 \mathrm{~mm}$ and consisted of $100^{3}$ elements (Fig. 1).

The WK sample was collected in the field at the site of a snow-profile measurement. The air was replaced with diethylphtalate, and the sample was frozen with dry ice. Afterwards 500 serial sections were cut; the thickness of the slices was $30 \mu \mathrm{m}$. The horizontal resolution of the 

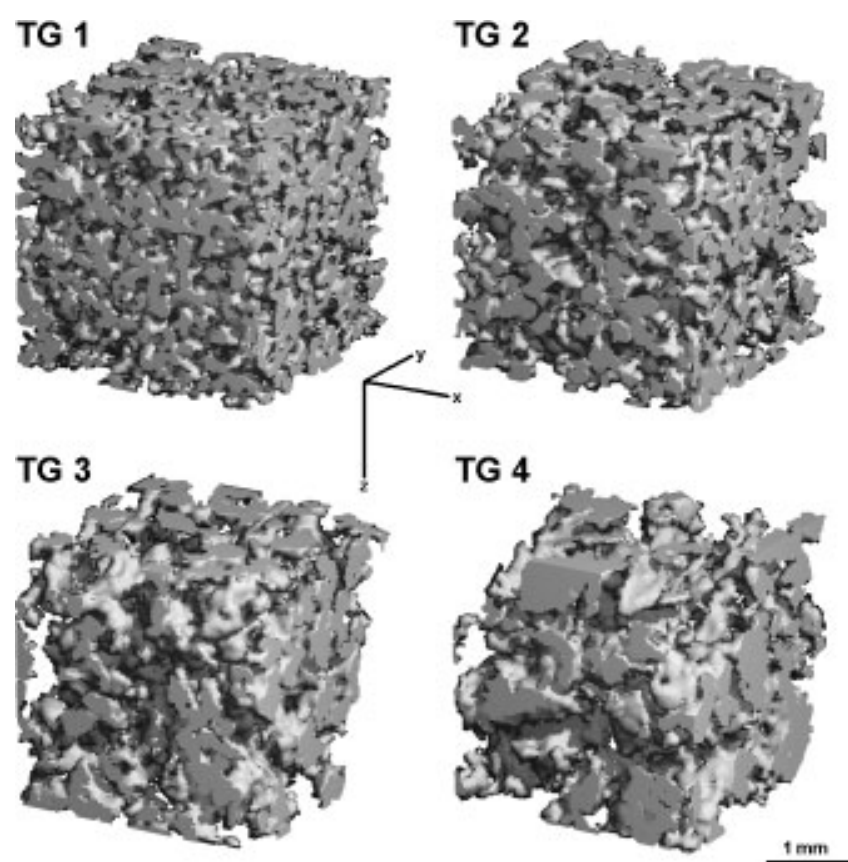

Fig. 1. Three-dimensional reconstruction of the $T G$ sample by $X$-ray microtomography. The sample was artificially metamorphosed and scanned non-destructively at four stages.

images was $15 \mu \mathrm{m}$ and was resampled to $30 \mu \mathrm{m}$. The segmentation of the images is based on the histogram. The segmentation threshold could not be checked by an independent density measurement due to the very different density of the layers. However, because of the clear bimodal histogram and good contrast of the digital images, a $10 \%$ variation of the threshold resulted in a $<5 \%$ change in the average density and was therefore not considered critical. The three-dimensional reconstruction was applied to the

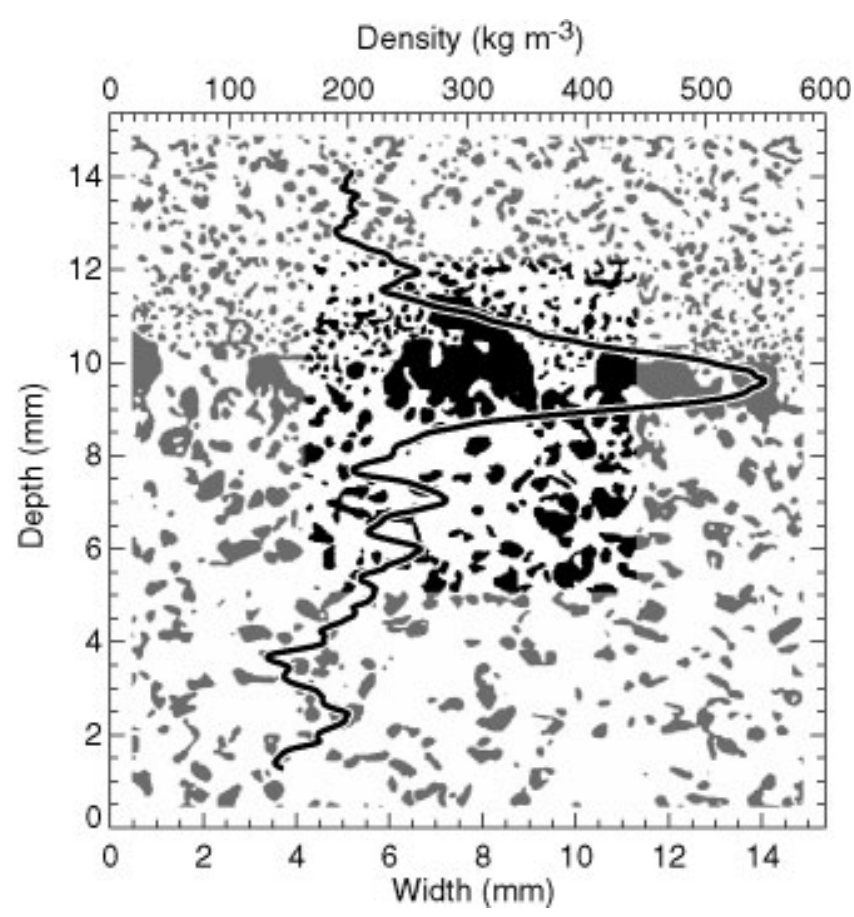

Fig. 2. Vertical planar section through sample WK. The subsection used for the simulation is in black, and the surrounding in grey. The horizontally averaged density is shown by the black line.
Table 1. Apparent stresses $\sigma$, apparent strains $\epsilon$ and elastic moduli $E$ for the $T G$ sample (density $243 \mathrm{~kg} \mathrm{~m}^{-3}$ )

\begin{tabular}{lccc}
\hline & $\sigma$ & $\epsilon$ & $E$ \\
& $\mathrm{kPa}$ & & $\mathrm{MPa}$ \\
\hline TG 1 & 194 & 0.0009 & 226 \\
TG 2 & 105 & 0.001 & 105 \\
TG 3 & 81 & 0.001 & 81.0 \\
TG 4 & 62 & 0.001 & 61.8 \\
\hline
\end{tabular}

central part of the sample consisting of rounded snow of small crystals, a melt crust forming a single grain layer and underlain by faceted crystals. The reconstructed cube had a side-length of $7.56 \mathrm{~mm}$ consisting of $252^{3}$ elements. The average volume fraction was 0.336 and varied along the vertical axis (Fig. 2).

\section{Finite-element modeling}

The most recent version of the FE program from Van Rietbergen and others (1996) was used. The digitized ice matrix was directly used to construct the eight-node brick elements. The number of elements was $0.3 \times 10^{6}$ for the TG samples and $5.4 \times 10^{6}$ for the WK sample. The Young's modulus of ice was taken as 9.5 GPa, and the Poisson ratio as 0.3 (Gammon and others, 1983; Sanderson, 1988). A uniaxial stress was simulated in the vertical direction, and boundary conditions at the other sides of the sample were without friction, like an unconfined compression test. The prescribed strain in the $z$ direction was 0.001 . The calculations were performed on a SunFire with four processors and 16 GB memory.

\section{RESULTS}

The simulated elastic moduli for the TG samples are shown in Table 1. Von Mises equivalent stresses are shown in the center along the $x z$-plane in Figure 3. Peak stresses in the ice matrix of the TG 1 sample were about four times higher than in the other samples. Stress concentrations occur along structures consisting of several grains. The locations of stress concentrations show a complex pattern, and are in many cases not at constrictions.

For the WK sample, as shown in Figure 4, higher von Mises equivalent stresses are found in the faceted snow below the melt crust. A few connections below the melt crust showed high stress concentrations. Several connections are loaded such that bending moments must occur.

\section{DISGUSSION}

The elastic moduli of the TG samples were about 10-100 times higher than have been measured from tests with strain rates of $10^{-3} \mathrm{~s}^{-1}$ (Mellor, 1975), but only 3-10 times larger than the values introduced in Figure 9 by Mellor (1980); in the latter case no strain rates are indicated. A probable explanation is that the effective elastic modulus is strongly dependent on strain rate. This behaviour is well known for ice (Sinha, 1978). Kry (1975) also observed a very strong dependence of the elastic modulus on strain rate. In this simulation, strain-rate dependency was not taken into account. 

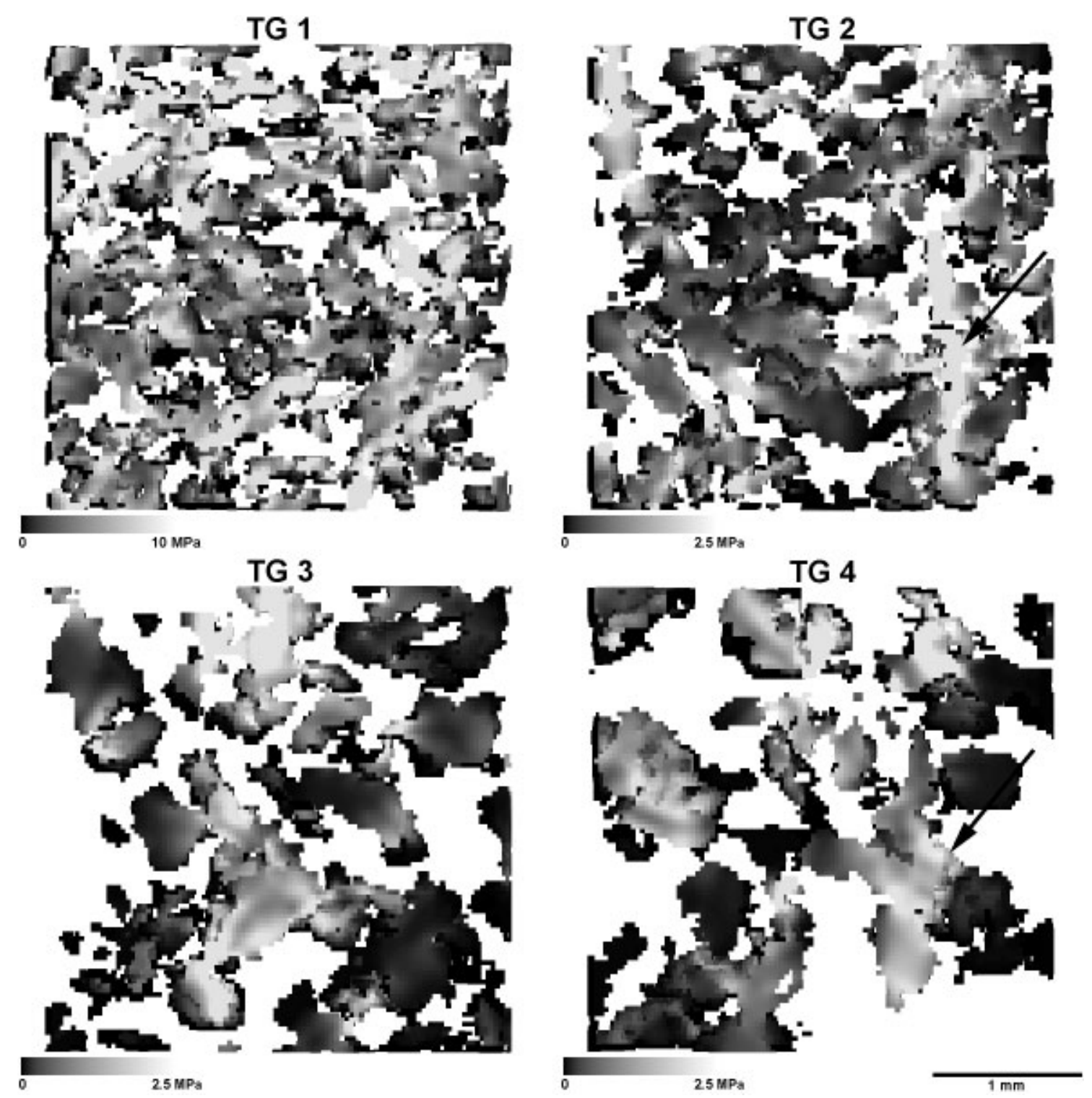

Fig. 3. Slices in the central xz-plane of the TG samples. Von Mises equivalent stresses are shown as greyscale. The pictured slice thickness is $0.36 \mathrm{~mm}$ (ten slices) to show the connections between the grains. Stress concentrations are indicated with arrows.
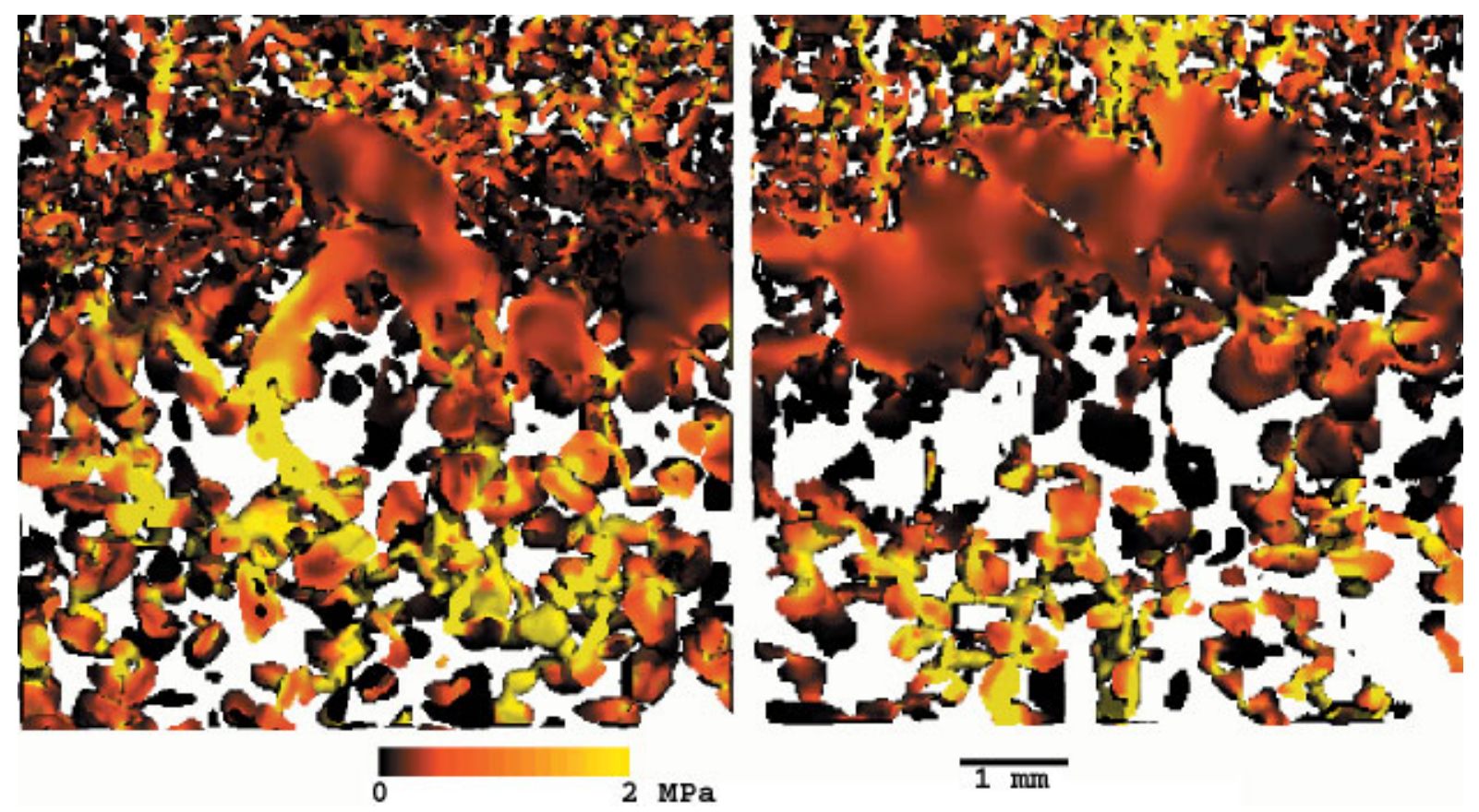

Fig. 4. Slices in the central xz (right) andyz (left) plane of the WK sample. Von Mises equivalent stresses are shown in color. The pictured slice thickness is $0.3 \mathrm{~mm}$. 
The calculated stresses nearly amounted to the strength of ice (around $10 \mathrm{MPa}$ (Sanderson, 1988)) at some locations, although the bulk strain was small. Fracture processes occur even at very small strains, as was observed from acoustic emissions (St. Lawrence, 1980). The effect of crystal boundaries cannot be considered with three-dimensional reconstructions since neither with serial sections nor with X-ray tomography are they visible. However, it is not known if this is relevant, considering the complex geometry observed in these samples. The elastic moduli, much larger than those that have been measured, are also relevant to fracture mechanics. In this study, the Young's modulus was taken for very high strain rates, as in a propagating fracture. This caused larger elastic moduli than measured and therefore a larger fracture toughness. Future experiments are needed to verify this numerical observation.

\section{AGKNOWLEDGEMENTS}

Special thanks to B. van Rietbergen for the FE program, B. Koller for help with visualization, and G. Krüsi for the serial sections. The manuscript was improved by the comments of M. Arakawa, an anonymous referee and the scientific editor, K. Nishimura.

\section{REFERENGES}

Coléou, C., B. Lesaffre, J.-B. Brzoska, W. Ludwig and E. Boller. 2001. Threedimensional snow images by X-ray microtomography. Ann. Glaciol., 32, 75-81.

Ford, C. M. and T. M. Keaveny. 1996. The dependence of shear failure properties of trabecular orientation. F. Biomechanics, 29(10), 1309-1317.
Gammon, P. H., H. Kiefte, M. J. Clouter and W.W. Denner. 1983. Elastic constants of artificial and natural ice samples by Brillouin spectroscopy. 7. Glaciol., 29(103), 433-460.

Kry, P. R. 1975. The relationship between the visco-elastic and structural properties of fine-grained snow. F. Glaciol., 14(72), 479-500.

Mellor, M. 1975. A review of basic snow mechanics. International Association of Hydrological Sciences Publication 114 (Symposium at Grindelwald 1974 Snow Mechanics), 251-291.

Mellor, M. 1980. Mechanical properties of polycrystalline ice. In Tryde, P., ed. Physics and Mechanics of Ice, IUTAM Symposium, Technical University of Denmark, Copenhagen, 6-10 August 1979. Berlin, Springer-Verlag. International Union of Theoretical and Applied Mechanics, 217-265.

St. Lawrence, W. F. 1980. The acoustic emission response of snow. F. Glaciol., 26(94), 209-216.

Sanderson, T. J. O. 1988. Mechanical properties of ice: laboratory studies. In Sanderson, T. J. O., ed. Ice mechanics: risks to offshore structures. London, etc., Graham and Trotman, 70-103.

Schneebeli, M. 2001. Three-dimensional snow: what snow really looks like. In ISSW 2000. International Snow Science Workshop, 1-6 October 2000, Big Sky, Montana. Proceedings. Bozeman, MT, American Avalanche Association, 407-408.

Schneebeli, M. 2002. The importance of the microstructure of snow in nature and engineering. In Brebbia, C.A., L.J. Sucharov and P. Pascolo, eds. Design and nature: comparing design in nature with science and engineering. Southampton, etc., WITpress, 87-93.

Shapiro, L. H., J. B. Johnson, M. Sturm and G. L. Blaisdell. 1997. Snow mechanics: review of the state of knowledge and applications. CRREL Rep. 97-3.

Sinha, N. K. 1978. Short-term rheology of polycrystalline ice. F. Glaciol., $21(85), 457-473$.

Sturm, M., J. Holmgren, M. König and K. Morris. 1997. The thermal conductivity of seasonal snow. F. Glaciol., 43(143), 26-41.

Van Rietbergen, B., H. Weinans, R. Huiskes and A. Odgaard. 1995. A new method to determine trabecular bone elastic properties and loading using micromechanical finite-element models. f. Biomechanics, 28(1), 69-81.

Van Rietbergen, B., H. Weinans, R. Huiskes and B. J.W. Polman. 1996. Computational strategies for iterative solutions of large FEM applications employing voxel data. Int. F. Numer. Methods Eng., 39, 2743-2767. 